\title{
Mensuração da ociosidade fabril pelos métodos ABC, TDABC e UEP
}

Measurement of industrial idleness by $A B C, T D A B C$ and $U E P$ methods

Medición de la ociosidad por métodos $A B C, T D A B C$ y $U E P$

\section{Rodney Wernke}

Doutor em Engenharia de Produção (UFSC)

Pesquisador do Grupo de Pesquisas em Empreendedorismo e Gestão de Micro e Pequenas

Empresas (GRUPEM/UNISUL)

Endereço: Av. José Acácio Moreira, 787 - Bairro Dehon

CEP: 88.704-900 - Tubarão/SC - Brasil

E-mail: rodneywernke1@hotmail.com

Telefone: (48) 99966-1472

\section{Ivone Junges}

Doutora em Engenharia de Produção (UFSC)

Professora no Curso de Relações Internacionais (UNISUL)

Endereço: Av. José Acácio Moreira, 787 - Bairro Dehon

CEP: 88.704-900 - Tubarão/SC - Brasil

E-mail: ivone.junges@unisul.br

Telefone: (48) 99976-4501

\section{Antonio Zanin}

Doutor em Engenharia de Produção (UFGRS)

Professor no PPGCCA (Unochapecó)

Endereço: Servidão Anjo da Guarda, 295-D, Bairro Efapi

CEP: 89.809-900 - Chapecó/SC - Brasil

E-mail: zanin@unochapeco.edu.br

Telefone: (49) 9980-0889

Artigo recebido em 20/12/2016. Revisado por pares em 18/03/2019. Reformulado em 25/03/2019. Recomendado para publicação em 25/03/2019 por Carlos Eduardo Facin Lavarda (Editor-Chefe). Publicado em 31/03/2019. 


\section{Resumo}

A partir do CPC-16 a contabilidade de custos deu mais atenção aos aspectos relacionados com as capacidades teórica, real e normal de produção, visto que o conhecimento destas é requerido para apurar o custo a ser atribuído aos produtos estocados ou vendidos. Nesse sentido, foi estabelecido como objetivo geral mensurar a ociosidade, de forma comparativa, pelos métodos UEP, ABC e TDABC no contexto de uma pequena empresa. A análise dos dados permitiu os seguintes resultados: alguns valores de custos unitários apurados pelos três métodos resultaram diferentes se apurados pela concepção original destes; nos três métodos é possível identificar a produção ociosa para atribuir-lhe valor monetário e verificar o percentual correspondente sobre a capacidade instalada.

Palavras-chave: Ociosidade produtiva; UEP; ABC; TDABC

\section{Abstract}

From the assumption of the CPC-16 the cost account was forced to give more attention to the aspects related with the theoretical capacity, real and normal of the production, since the knowledge of these is required to investigate the cost to be attributed to the stocked or sold products. In this way, it was established as general objective to measure the idleness, by comparative form, by UEP, ABC and TDABC methods in a small company context. The data analyses allowed the following results: some units cost value determined by the three methods result different if determined by the original conception of these; in the three methods is possible to identify the otiose production to assign it monetary value and verify the corresponding percentage about the installed capacity.

Keywords: Production idleness; UEP; $A B C$; TDABC

\section{Resumen}

A partir del CPC-16 la contabilidad de costos dio más atención a los aspectos relacionados con las capacidades teórica, real y normal de producción, ya que el conocimiento de estas se requiere para determinar el costo a ser atribuido a los productos almacenados o vendidos. En este sentido, se estableció como objetivo general medir la ociosidad, de forma comparativa, por los métodos UEP, ABC y TDABC en el contexto de una pequeña empresa. El análisis de los datos permitió los siguientes resultados: algunos valores de costes unitarios constatados por los tres métodos resultaron diferentes si se determinaron por la concepción original de éstos; en los tres métodos es posible identificar la producción ociosa para asignarle valor monetario y verificar el porcentaje correspondiente sobre la capacidad instalada.

Palabras clave: Ociosidad productiva; UEP; $A B C$; TDABC

\section{Introdução}

A possibilidade de mensurar o nível de ociosidade produtiva e atribuir um valor monetário para esse fator era uma prioridade maior para os gerentes de produção das indústrias do que para os contadores dessas empresas. Contudo, a partir dos pressupostos do Pronunciamento Técnico CPC-16 (R1), cujo teor está correlacionado às Normas Internacionais de Contabilidade - IAS 2 - IASB e descrito na NBC TG 16(R2), item 13, de 24/11/2017, a contabilidade de custos deve considerar também os aspectos relacionados com as capacidades teórica (ou instalada), real e normal de produção, visto que o conhecimento destas é requerido para apurar contabilmente o custo a ser atribuído aos produtos estocados ou vendidos.

A determinação do custo fabril, para efeito contábil, costuma ser efetuada utilizando os procedimentos preconizados pelo Custeio por Absorção (IUDÍCIBUS et al., 2010). Contudo, do ponto de vista da gestão empresarial o referido método tem sofrido críticas quanto à qualidade da informação proporcionada (KAPLAN; COOPER, 1998; SHANK; 
GOVINDARAJAN, 1997), especialmente pela arbitrariedade relacionada com a escolha dos critérios de rateio (SCHULTZ; SILVA; BORGERT, 2008; MARTINS; ROCHA, 2010). Assim, metodologias de custeamento como ABC (Activity-based Costing), TDABC (Timedriven Activity-based Costing) e UEP (Unidades de Esforço de Produção) têm sido priorizadas gerencialmente (BORNIA, 2009; SOUZA; DIEHL, 2009), em detrimento do Custeio por Absorção.

Nesse contexto, se esses métodos de custeio proporcionam informações de custos com qualidade mais adequada do ponto de vista gerencial que o Custeio por Absorção (FONTOURA, 2013; PINZAN, 2013; PEREIRA, 2015), é razoável cogitar que a mensuração da ociosidade seria tecnicamente mais consistente também. Contudo, os três métodos citados possuem características que distinguem-se substancialmente, tanto em termos dos procedimentos de alocação de custos (equivalência de produção no UEP, consumo de atividades no $\mathrm{ABC}$ e consumo de tempos no TDABC, por exemplo), quanto em relação aos conceitos que empregam (como custo de transformação no UEP, custo das atividades no $\mathrm{ABC}$ e taxa de capacidade no TDABC). Em decorrência disso é coerente supor que, a priori, conduzirão a valores díspares de custos unitários dos produtos e de ociosidade fabril.

A partir desse contexto, emerge a questão de pesquisa que se pretende responder neste estudo: os níveis de ociosidade fabril, em valor monetário (R\$) e em percentual (\%) da capacidade instalada, serão diferentes se mensurados pelos métodos UEP, ABC e TDABC? Para essa finalidade foi estabelecido o objetivo de mensurar a ociosidade, comparativamente, pelos métodos UEP, ABC e TDABC no contexto de pequena empresa que atua como lavanderia.

Um estudo com esse enfoque se justifica por, pelo menos, duas razões. A primeira é a escassa publicação de artigos sobre a mensuração da ociosidade fabril na literatura contábil brasileira, como será destacada em seção vindoura, o que constitui uma lacuna de pesquisa a ser explorada. A segunda razão é que os métodos mais utilizados na contabilidade gerencial (UEP, $\mathrm{ABC}$ e TDABC) tendem a produzir resultados mais consistentes ou confiáveis na comparação com os valores oriundos do método de Custeio por Absorção, priorizado na contabilidade de custos para atender às normas preconizadas pelo Fisco.

\section{Revisão da Literatura}

Bettinghaus, Debruine e Sopariwala (2012) afirmam que o custo da capacidade ociosa é uma informação relevante para os gestores e investidores. Algumas empresas calculam as informações para fins internos, enquanto que analistas externos também tentam estimar os custos de capacidade ociosa. Mas, na seara contábil, a adesão do Brasil ao padrão internacional de contabilidade (IFRS) acarretou a adoção do CPC-16-Estoques, cujo conteúdo adequou-se aos ditames do IAS 2-Estoques, que é uma norma internacional de contabilidade emitida pelo IASB. Nesse rumo, a NBC TG 16 (R2) - item 13, recomenda a utilização pela contabilidade de custos dos conceitos de capacidade total (teórica), capacidade normal e capacidade real.

Sobre esse tema, Atadaine Sobrinho (2010) argumenta que a expressão capacidade teórica se refere ao volume de produção que pode ser atingido quando o equipamento opera com sua capacidade máxima, sem a ocorrência de qualquer falha do equipamento ou de quem opera. Em termos práticos, é uma situação difícil de ocorrer e tem utilidade somente como um parâmetro para se saber em que nível o equipamento está operando com relação ao padrão considerado ideal. No caso da capacidade normal, são considerados alguns fatores limitantes do equipamento e/ou do operador (dentro das condições normais de trabalho), sendo esta a métrica mais utilizada nas empresas para determinar as variações da ociosidade. Quanto à capacidade real, esta equivale à capacidade efetivamente utilizada de produção e considera o quanto deve ser produzido para atender as reais necessidades demandadas pela empresa. 
Mesmo tendo ganhado mais notoriedade no âmbito contábil a partir do CPC-16, Bornia (1995) já havia discorrido sobre a filosofia do Custeio por Absorção Ideal e defendia que desperdícios como a ociosidade fabril não deveriam ser incorporados ao custo dos produtos, como ocorria por meio do Custeio por Absorção Integral. Mais recentemente, Martins e Rocha (2010) abordaram aspectos ligados ao uso da capacidade produtiva normal na determinação dos custos fixos unitários dos produtos, destacando que utilizar a capacidade instalada para determinar o custo fixo unitário acarretaria redução deste valor.

Quanto ao método de custeio para efetuar a alocação dos custos de transformação aos produtos, mesmo existindo diversos métodos e critérios de avaliação da produção, Iudícibus et al. (2010, p.505) asseveram que "dentro dos princípios fundamentais da contabilidade, consagrados pela Lei no. 6.404/76 e pelo Pronunciamento Técnico CPC 16 - Estoques, o método de custeio real por absorção é o indicado". Por outro lado, a pesquisa de Schultz, Silva e Borgert (2008) aduz que qualquer método de custeio adaptável à legislação vigente pode ser utilizado para a determinar o custo contábil, bem como para valorar os estoques. Alicerçam esse posicionamento no aspecto de que não há orientação que especifique algum método de custeio como obrigatório nas normas tributárias, contábeis ou societárias vigentes.

Entretanto, mesmo com a utilização mais disseminada do Custeio por Absorção na contabilidade de custos, os métodos $\mathrm{ABC}$, TDABC e UEP têm sido priorizados na contabilidade gerencial com o intuito de aprimorar o custeamento dos produtos.

\subsection{Principais características dos métodos utilizados na pesquisa}

No que tange ao ABC, Kaplan e Cooper (1998) afirmam que este prioriza a identificação das atividades organizacionais mais relevantes com o objetivo de aprimorar a determinação dos custos e da lucratividade da organização. Para Schmidt, Santos e Leal (2009) este método busca entender a formação de todos os custos necessários à obtenção de determinado produto e alocálos a partir do consumo das atividades pelos produtos, para uma melhor avaliação de custos.

Porém, Kaplan e Anderson (2007) argumentam que a implementação do ABC apresenta as seguintes deficiências: os processos de entrevistas e levantamentos de dados são demorados e dispendiosos; os dados necessários ao $\mathrm{ABC}$ são subjetivos e de difícil validação; o armazenamento, o processamento e a apresentação dos dados são dispendiosos; a maioria dos modelos $\mathrm{ABC}$ foca processos específicos e não fornece uma visão integrada das oportunidades de lucro em todo o âmbito da empresa; o modelo $\mathrm{ABC}$ não é adaptável facilmente às novas circunstâncias, além de incorrer no erro teórico de ignorar a possibilidade de capacidade ociosa.

Sobre o método UEP, Slavov (2013) cita que este foca o custo de transformação de operações homogêneas executadas em postos operativos, geralmente em fábricas com mix de produção diversificado. Gantzel e Allora (1996) enfatizam que referido método possibilita, por meio de uma única unidade de medida, mensurar toda e qualquer produção, por mais diversificada que seja. Souza e Diehl (2009) aduzem que na implementação do UEP devem ser percorridas as seguintes fases: dividir a empresa em postos operativos (PO); calcular os potenciais de produção dos postos operativos (foto-índices dos postos operativos - FIPO); selecionar o produto-base; cálculo do foto-custo do produto-base; determinação dos potenciais produtos dos postos operativos e cálculo do valor dos produtos em UEPs.

Acerca dos pontos positivos do UEP, Bornia (2009) assevera que o UEP possibilita o acompanhamento da produção com o uso de medidas físicas, sendo três os tipos de indicadores que podem ser utilizados para essa finalidade: eficiência, eficácia e produtividade horária. A eficiência diz respeito ao nível de produção alcançado (em UEPs), comparado com a produção (em UEPs) que poderia ser atingida no período de expediente disponível. A eficácia vincula a produção obtida com a produção que teoricamente se deveria obter no expediente trabalhado 
efetivamente e a produtividade horária é apurada pela divisão da produção do período pelo tempo de trabalho.

Entretanto, Pereira (2015) elenca como limitações do UEP os seguintes aspectos: não identifica a parcela de custos associados a perdas do processo; necessita revisão constante dos cálculos e da estrutura de produção; desconsidera as despesas de estrutura; tende a ser aplicável apenas ao ambiente industrial; não permite gerenciar os gastos não fabris; apresenta dificuldades de aplicação em empresas onde os produtos variam regularmente; tem elevada complexidade e custo de implementação; necessita de operações relativamente padronizadas; apresenta subjetividade na escolha do produto-base; não abrange gastos de overhead (como logística de suprimento, controle de qualidade etc.), entre outras.

O terceiro método envolvido nesta pesquisa é o TDABC que, conforme Kaplan e Anderson (2007), foi aplicado inicialmente em 1997. Para sua implementação, Everaert e Bruggeman (2007) afirmam que o TDABC requer os seguintes passos: levantar os recursos fornecidos às atividades, segregando-os em grupos; apurar o valor gasto com cada recurso; mensurar a capacidade prática das atividades; determinar o custo unitário de cada recurso, com a divisão do valor encontrado para cada grupo de recursos pela capacidade prática da atividade (calculado no item anterior); aferir o tempo consumido para execução de uma atividade e multiplicar o custo unitário pelo tempo requerido por cada objeto de custo.

Sobre os pontos positivos e negativos associáveis ao TDABC, os estudos de Anderson e Kaplan (2007), Cardinaels e Labro (2008), Ratnatunga, Tse e Balachandran (2012), Campanale, Cinquini e Tenucci (2014) e Kaplan (2014) apontaram como desvantagens mais relevantes a $(i)$ dificuldade para obter estimativas de tempos precisas e (ii) a necessidade de utilizar uma grande base de dados para determinar os tempos de cada atividade executada e suas variações em empresas com muitas etapas produtivas. Por outro lado, os citados autores aventaram os seguintes benefícios: simplificação em relação ao $\mathrm{ABC}$; grande facilidade para adaptar e alimentar softwares que envolvam o TDABC; possibilidade de determinar a utilização das capacidades instalada e ociosa; facilmente adaptável a contextos empresariais complexos; identificação de oportunidades de melhoria; elaboração de previsões sobre gastos com determinado tipo de produto ou cliente; aprimoramento da eficiência da utilização dos recursos; rapidez no processamento dos dados requeridos e possibilidade de utilizar diversas taxas de direcionadores (driver rates) para determinar o custo de cada atividade priorizada.

\subsection{Pesquisas assemelhadas}

$\mathrm{Na}$ literatura brasileira da área de custos é possível encontrar publicações que compararam métodos de custeio, mas têm sido priorizados os comparativos envolvendo aqueles mais conhecidos (como o Absorção, o Variável/Direto e o ABC). Destarte, os métodos menos presentes nos livros desta seara, como o TDABC e o UEP, não têm recebido a mesma atenção em termos de estudos comparativos, mesmo que possuam vários pontos positivos e até alguns aspectos superiores aos demais, do ponto de vista gerencial.

Entre os artigos e livros publicados no Brasil que fazem comparativos envolvendo dois ou mais métodos de custeio cabe destacar os citados, resumidamente, no Quadro 1. Entretanto, publicações que priorizassem a comparação, concomitante, dos métodos $\mathrm{ABC}$, TDABC e UEP em termos da mensuração da ociosidade fabril não foram encontradas nas buscas realizadas na primeira semana de dezembro de 2015 nas plataformas de pesquisa "Portal de Periódicos Capes", "EBSCO (Business Source Complete)", "Web of Science" e "Science Direct". 
Quadro 1 - Publicações que compararam métodos de custeio

\begin{tabular}{|c|c|}
\hline Autoria & Foco \\
\hline Rucinski (1996) & Identificou similaridades entre ABC e UEP \\
\hline Sabadin, Grunow e Fernandes (2005) & Abordou a integração entre os métodos ABC e UEP \\
\hline Machado, Borgert e Lunkes (2006) & Ensaio sobre método híbrido envolvendo ABC e UEP \\
\hline Silva (2006) & Propôs método híbrido entre ABC e UEP \\
\hline Malaquias et al. (2007) & Comparativo teórico de UEP, Absorção, Variável e Padrão \\
\hline Kaplan e Anderson (2007) & Enfatiza as diferenças entre TDABC e ABC \\
\hline Dalmácio, Rezende e Aguiar (2007) & TDABC versus ABC em hospital \\
\hline Schultz, Silva e Borgert (2008) & Uso do Absorção, ABC e UEP na contabilidade de custos \\
\hline Campagnolo, Souza e Kliemann (2009) & Cenário hipotético sobre a aplicação do UEP e do TDABC \\
\hline Silva, Borgert e Schultz (2009) & Uso conjunto de UEP e TDABC em procedimento médico \\
\hline Martins e Rocha (2010) & $\begin{array}{c}\text { Compara métodos de custeio tradicionais, sem abordar o } \\
\text { TDABC e o UEP em detalhes }\end{array}$ \\
\hline Wernke, Mendes e Lembeck (2010) & TDABC versus ABC em setor de manutenção \\
\hline Peixe, Bornia e Martins (2010) & Uso conjunto (não comparativo) do ABC e do UEP \\
\hline Confessor et al. (2010) & Comparação sobre a teoria do UEP com o francês UVA \\
\hline Mauricio e Cavenaghi (2011) & UEP versus Custeio Variável em empresa termoplástica \\
\hline Pereira $(2011)$ & TDABC X ABC X Absorção em indústria de bebidas \\
\hline Moraes $(2011)$ & Diferenças e semelhanças entre ABC e TDABC \\
\hline Pacassa e Schultz (2012) & TDABC versus ABC versus Absorção \\
\hline Pinzan $(2013)$ & Estudo de casos múltiplos com Absorção, Variável e ABC \\
\hline Fontoura (2013) & Variável, Absorção, ABC e UEP \\
\hline Ambrogini, Albuquerque e Souza (2014) & Absorção, Variável e ABC em consultório médico \\
\hline Gonçalves et al. (2014) & Absorção, Variável e ABC em escola estadual. \\
\hline Wernke, Junges e Lembeck (2015) & TDABC versus UEP em facção têxtil \\
\hline Pereira (2015) & $\begin{array}{c}\text { Similaridades, diferenças e complementaridades entre } \mathrm{ABC} \text { e } \\
\text { UEP, com exemplo numérico fictício }\end{array}$ \\
\hline
\end{tabular}

Fonte: elaborado pelos autores.

Nessas pesquisas online foram empregadas as palavras-chave "ociosidade" ou "capacidade ociosa" em conjunto com os acrônimos dos métodos em lume ("ABC", "TDABC" e "UEP") ou suas descrições por extenso, bem como a versão destas para o inglês (quando cabível), acrescidas do símbolo "*” (asterisco) para permitir derivações dos termos usados. Assim, os resultados oriundos das buscas online apontaram os estudos sintetizados no Quadro 2 como aqueles que mais se aproximavam do tema deste artigo.

\begin{tabular}{|c|c|}
\hline Autoria & \begin{tabular}{|r|r} 
Foco do estudo \\
\end{tabular} \\
\hline $\begin{array}{l}\text { Buchheit } \\
(2003)\end{array}$ & $\begin{array}{l}\text { Experimento com } 68 \text { estudantes sobre os efeitos de divulgar ou não a capacidade } \\
\text { ociosa de empresa fictícia, sem uso de método de custeio específico. }\end{array}$ \\
\hline $\begin{array}{c}\text { Giri e } \\
\text { Moon (2004) }\end{array}$ & $\begin{array}{l}\text { Focalizaram o custo da capacidade ociosa na definição dos lotes econômicos de compra } \\
\text { por meio de exemplos numéricos fictícios, sem usar método de custeio. }\end{array}$ \\
\hline $\begin{array}{l}\text { Tse e Gong } \\
\text { (2009) }\end{array}$ & $\begin{array}{l}\text { Modelo hipotético para converter os resultados do } \mathrm{ABC} \text { para os modelos } \mathrm{TDABC} \text { e } \\
\mathrm{RCA} \text { (Resource Consumption Accounting) quanto ao custo alocado e à capacidade } \\
\text { ociosa. }\end{array}$ \\
\hline $\begin{array}{l}\text { Popesko } \\
(2009)\end{array}$ & $\begin{array}{l}\text { Método de programação linear para estimar o valor do custo da ociosidade de } \\
\text { companhia aérea (pelo } \mathrm{ABC} \text { ), sem utilizar exemplo numérico ou dados reais nessa } \\
\text { proposição. }\end{array}$ \\
\hline $\begin{array}{l}\text { Duarte, Pinto e } \\
\text { Lemes (2009) }\end{array}$ & $\begin{array}{l}\text { Exemplo hipotético sobre o uso da Teoria das Filas para minimizar o problema do } \\
\text { TDABC que considera que a capacidade prática seria entre } 80 \% \text { e } 85 \% \text {, segundo seus } \\
\text { idealizadores. A teoria das filas seria uma forma prática para estimar o real tempo que o } \\
\text { sistema se encontra ocioso, eliminando a subjetividade dos cálculos de custeio. }\end{array}$ \\
\hline $\begin{array}{l}\text { Schmidt, Santos e } \\
\text { Leal (2009) }\end{array}$ & $\begin{array}{l}\text { Exemplo numérico fictício que comparou ABC e TDABC, com apenas um exemplo de } \\
\text { cálculo sobre a ociosidade no TDABC. }\end{array}$ \\
\hline $\begin{array}{l}\text { Ewer, Keller e } \\
\text { Olson (2010) }\end{array}$ & $\begin{array}{l}\text { Utilização da capacidade (ou não) no cálculo dos custos a partir das normas do } \\
\text { Financial Accounting Standards Board (FASB) acerca do SFAS no. } 151\end{array}$ \\
\hline
\end{tabular}




\begin{tabular}{|c|l|}
\hline Autoria & \multicolumn{1}{c|}{ Foco do estudo } \\
\hline $\begin{array}{c}\text { Bettinghaus, } \\
\text { Debruine e } \\
\text { Sopariwala (2012) }\end{array}$ & $\begin{array}{l}\text { Sem mencionar método de custeio específico, com dados de 2002 a 2008 da montadora } \\
\text { GM norte-americana, salientaram a importância do conhecimento da capacidade ociosa } \\
\text { como informação para usuários internos e externos das demonstrações contábeis. }\end{array}$ \\
\hline $\begin{array}{c}\text { Silva e } \\
\text { Leite (2013) }\end{array}$ & $\begin{array}{l}\text { Pelo método dos Centros de Custos (RKW), com dados reais de fábrica de embalagens, } \\
\text { apuraram os custos dos produtos com e sem o cômputo da capacidade ociosa. }\end{array}$ \\
\hline $\begin{array}{c}\text { Eckert et } \\
\text { al. } \text { (2013) }\end{array}$ & $\begin{array}{l}\text { Em indústria de calçados brasileira, apuraram o percentual de ociosidade em números } \\
\text { de pares e multiplicaram pelo valor total de custos fixos para apurar o valor monetário } \\
\text { da capacidade ociosa (sem menção a método de custeio). }\end{array}$ \\
\hline $\begin{array}{l}\text { Wernke, Cláudio } \\
\text { e Junges (2013) }\end{array}$ & $\begin{array}{l}\text { Por intermédio do UEP, foram mensurados indicadores não-financeiros como } \\
\text { produtividade e ociosidade numa pequena fábrica de material elétrico. }\end{array}$ \\
\hline
\end{tabular}

Fonte: elaborado pelos autores.

Como visto, há uma lacuna de pesquisa relacionada à comparação entre os três métodos visados, pois nenhuma publicação tratou sobre a mensuração da ociosidade fabril desse modo.

\section{Metodologia}

A pesquisa em lume pode ser classificada como um estudo de caso porque, conforme Yin (2010), este tipo de procedimento equivale a uma investigação empírica sobre um fenômeno contemporâneo dentro de seu contexto de vida real, especialmente quando os limites entre o fenômeno e o contexto não estão claramente definidos. Quanto à forma de abordagem do problema o estudo pode ser classificado como "qualitativo", visto que se equipara ao que Richardson (1999) conceitua para os estudos que descrevem a complexidade de determinado problema, que analisam a interação de certas variáveis, que compreendem e classificam os processos dinâmicos vividos por grupos sociais. Então, a partir dos dados quantitativos (contábeis, financeiros e físicos) coligidos, foi realizada uma análise qualitativa por meio do estudo comparativo entre os três métodos de custeio enfocados.

Em relação à tipologia quanto aos objetivos esta pesquisa é classificável como descritiva porque, para Gil (1999), essa modalidade visa descrever características de determinada população ou fenômeno, ou o estabelecimento de relação entre as variáveis envolvidas. Além disso, Andrade (2002) salienta que essa categoria de pesquisa se preocupa em observar os fatos, registrá-los, analisá-los, classificá-los e interpretá-los sem que o pesquisador intervenha.

Quanto à escolha da empresa, esta ocorreu por dois motivos. A primeira razão está ligada à possibilidade de acesso aos dados necessários por parte dos pesquisadores, facultada pelo proprietário do empreendimento. A segunda razão para escolhê-la é que esta possui estrutura produtiva com apenas dez setores e trabalhava com mix composto somente por cinco produtos. Essa configuração acarretou maior facilidade na coleta de dados e na elaboração dos cálculos necessários, bem como proporcionou melhores condições de redigir um texto detalhado abrangendo todos os setores e produtos.

No que concerne à coleta de dados, Marques, Camacho e Alcantara (2015) afirmam que nos estudos de caso, para realizar a coleta de dados, é possível combinar métodos como entrevistas, pesquisas em arquivos, questionário, relatórios verbais e observações, sendo que as evidências podem ser qualitativas e quantitativas. Nesta pesquisa os procedimentos de coleta de dados foram realizados em novembro de 2015, abrangendo o contexto de outubro de 2015 . Para tanto, foram empregadas as técnicas de conversas informais (entrevistas não estruturadas) com o gestor da entidade e com o contador e foi efetuada uma análise documental (nos controles internos e na contabilidade terceirizada) com a intenção de conhecer a situação vigente no que tange aos dados necessários para efetuar o estudo pretendido. Na sequência, iniciou-se a coleta dos dados requeridos para execução do trabalho nos controles internos existentes, além de outros informes mais específicos que foram obtidos junto ao gerente e ao contador da firma. 
Portanto, com a intenção de ilustrar a mensuração da ociosidade pelos métodos UEP, $\mathrm{ABC}$ e TDABC, apresenta-se a seguir o estudo de caso realizado na lavanderia de pequeno porte "Beta" (denominação fictícia para preservar a empresa), sediada em município do litoral catarinense. Pelas características de sua atividade, esse tipo de empreendimento requer investimentos em ativos (maquinários, móveis, equipamentos e capital de giro) que podem ficar parcialmente ociosos durante determinado período, a depender da demanda existente. Em virtude disso, foi proposto ao administrador que o nível de ociosidade fosse mensurado, visto que até então não era apurado o valor monetário respectivo na empresa em lume.

Com essa finalidade, o proprietário permitiu aos pesquisadores levantar os dados requeridos, sendo que para a conclusão do estudo foram percorridos alguns passos. A coleta dos dados necessários envolveu procedimentos relacionados com a segmentação da estrutura da empresa em postos operativos, atividades e setores para se adequar, respectivamente, aos métodos UEP, ABC e TDABC. Na sequência foram apurados os valores de custos destas unidades operacionais em termos de depreciação econômica dos equipamentos, salários e encargos, aluguel predial, energia elétrica e manutenção do maquinário. Em seguida, na fase de cálculo do custo de cada produto e da ociosidade fabril foi necessário calcular o custo unitário de cada produto pelos três métodos e, em seguida, medir a ociosidade do período com os dados disponíveis. Por último, a etapa de análise e interpretação dos resultados consistiu avaliar os resultados apurados em termos dos custos unitários atribuídos aos produtos e dos valores calculados para a ociosidade do período por meio do UEP, ABC e TDABC e compará-los.

Por outro lado, no que tange aos aspectos formais, no sentido de avaliar o rigor metodológico deste estudo de caso foram utilizados os parâmetros recomendados no artigo de Marques, Camacho e Alcantara (2015) quanto ao objeto de estudo, coleta e análise de dados, bem como quanto aos resultados oriundos.

\section{Aplicação dos métodos UEP, ABC e TDABC na empresa pesquisada}

O ponto de partida para obtenção dos dados que fundamentaram o estudo foi identificar os custos das dez unidades produtivas nas quais a empresa estava segregada. Para facilitar a análise comparativa, assumiu-se que estas teriam a mesma subdivisão no contexto das três metodologias, ou seja, que postos operativos (no UEP) seriam equivalentes às atividades executadas (no $\mathrm{ABC}$ ) e aos setores (no TDABC). Em seguida, foram alocados os valores dos custos mensais (R\$) de cada uma das subdivisões da lavanderia (considerando-se expediente mensal de 198 horas disponíveis), conforme expresso na Tabela 1.

Tabela 1 - Custo por hora dos postos operativos, atividades e setores

\begin{tabular}{l|r|r|r|r|r|r|r|r}
\hline & $\begin{array}{r}\text { Deprec. } \\
\text { Máq.R\$ }\end{array}$ & $\begin{array}{r}\text { Aluguel } \\
\text { Pred.R\$ }\end{array}$ & $\begin{array}{r}\text { Salários e } \\
\text { Encarg.R\$ }\end{array}$ & $\begin{array}{r}\text { Energia } \\
\text { Elétr.R\$ }\end{array}$ & $\begin{array}{r}\text { Manut. } \\
\text { Máq.R\$ }\end{array}$ & $\begin{array}{r}\text { a) Gasto do } \\
\text { Mês R\$ }\end{array}$ & $\begin{array}{r}\text { b) Exped. } \\
\text { do Mês (h) }\end{array}$ & $\begin{array}{r}\mathrm{c}=\mathrm{a} / \mathrm{b}) \text { Custo } \\
\text { por Hora R\$ }\end{array}$ \\
\hline Entr.Pç./Micro+Impress. & 155,72 & 321,11 & $1.651,07$ & 28,91 & 70,00 & $2.226,81$ & 198 & 11,2465 \\
Entr.Pç./Balança Dig. & 27,08 & 11,06 & 505,41 & 0,41 & - & 543,96 & 198 & 2,7473 \\
Manual/Sep. Peças & - & 594,02 & 270,00 & - & - & 864,02 & 198 & 4,3637 \\
Lavagem/Lavadora & 475,00 & 290,15 & 405,00 & 142,48 & 301,00 & $1.613,63$ & 198 & 8,1497 \\
Secagem/Secadora & 208,33 & 280,42 & 405,00 & 706,48 & 119,00 & $1.719,23$ & 198 & 8,6830 \\
Passadoria/Mesa de passar & 180,21 & 453,81 & $1.080,00$ & 497,58 & 105,00 & $2.316,59$ & 198 & 11,7000 \\
Embalag./Embal.Roupas & 52,08 & 132,69 & 270,00 & 13,49 & 35,00 & 503,26 & 198 & 2,5417 \\
Armaz./Cabideiro Eletr. & 120,50 & 537,84 & 67,50 & 8,51 & 70,00 & 804,35 & 198 & 4,0624 \\
Armaz./Manual-Prat.MDF & 69,44 & 457,79 & 202,50 & - & - & 729,73 & 198 & 3,6855 \\
Saída Pç./Micro-comp. & 66,11 & 321,11 & $1.148,52$ & 4,52 & - & $1.540,27$ & 198 & 7,7792 \\
\hline Totais & $1.354,49$ & $3.400,00$ & $6.005,00$ & $1.402,37$ & 700,00 & $12.861,86$ & \multicolumn{5}{c}{-} & - \\
\hline
\end{tabular}

Fonte: elaborada pelos autores.

No que tange ao volume de produção, verificou-se nos controles internos que a entidade trabalhou no mês do estudo com cinco tipos de produtos (ou serviços): lavagem de edredon 
(295 peças), lavagem de camisas (413 peças), lavagem de ternos (166 peças), lavagem de roupas mais simples "com" passar a ferro $(374 \mathrm{~kg})$ e lavagem de roupas mais simples "sem" passar a ferro $(292 \mathrm{~kg})$. Então, a partir desses dados iniciais foram apurados os custos de cada produto pelas três metodologias de custeio como relatado, sinteticamente, na sequência.

Quanto ao método UEP, neste foram percorridas as seguintes etapas: cálculo do custo por hora (em R\$) de cada posto operativo; mensuração do tempo de passagem dos produtos em cada posto operativo; definição do "L. Edredon (pç.)" como produto-base; determinação dos potenciais produtivos (em UEP por hora) dos postos operativos; apuração do equivalente em UEP para cada produto; levantamento do total de UEPs produzidas no mês; cálculo do valor unitário da UEP do período (que foi de R \$13,0974) e cálculo do custo unitário de transformação (em R \$) de cada produto, multiplicando o respectivo equivalente em UEP pelo valor monetário (R\$) da UEP no mês.

Para empregar o ABC foram utilizados os seguintes passos: cálculo do custo mensal de execução de cada atividade (antepenúltima coluna da Tabela 1); escolha dos direcionadores de atividades; apuração do volume mensal de execução de cada atividade; alocação dos custos das atividades aos produtos pelo número de execuções das atividades consumidas pelos mesmos e cálculo do custo unitário de cada produto pela divisão do valor do custo total atribuído (R\$) pelo volume produzido de cada item (peças ou quilos, conforme o tipo de produto).

No que concerne à utilização do TDABC foram adotados os procedimentos a seguir: $(i)$ cálculo do custo mensal da capacidade instalada de cada setor (antepenúltima coluna da Tabela 1); (ii) levantamento do número de minutos disponíveis no expediente mensal de 198 horas (198 horas X 60 minutos = 11.880 minutos por mês), o que corresponde à "capacidade prática dos setores" na nomenclatura utilizada nessa metodologia; (iii) determinação da taxa do custo da capacidade prática (dividindo-se o valor do custo mensal de cada setor, apurado na Tabela 1, pelo número de minutos disponíveis no período, calculado na etapa precedente); (iv) definição do consumo de minutos em cada setor, por produto (tempo de produção) e apurar o custo unitário dos produtos nos setores (ao multiplicar o valor monetário da taxa de capacidade do setor pelo número de minutos do setor despendidos para produzir cada item).

Da aplicação desses três métodos no contexto pesquisado resultaram valores de custos unitários diferentes para cada produto, como exposto na Tabela 2.

Tabela 2 - Comparativo do custo unitário (R\$) dos produtos

\begin{tabular}{lrrrr}
\hline & UEP & TDABC & ABC \\
Produtos & Custo Unit. R\$ & Custo Unit. R\$ & Custo Unit. R\$ \\
\hline L. Edredon (pç.) & 13,097 & 3,925 & 11,139 \\
L. Camisa (pç.) & 5,363 & 1,607 & 7,797 \\
L. Terno (pç.) & 7,672 & 2,299 & 8,872 \\
L. Roup/Pas. (kg) & 9,557 & 2,864 & 8,391 \\
L. Roup/S/Pas. (kg) & 6,628 & 1,986 & 5,975 \\
\hline
\end{tabular}

Fonte: elaborada pelos autores.

O cenário delineado na Tabela 2 mostrou que os custos unitários pelo UEP apresentaram valores mais assemelhados àqueles calculados pelo $\mathrm{ABC}$, enquanto que os resultados apurados pelo TDABC divergiram significativamente, se comparados aos outros dois métodos.

Mesmo que o foco prioritário desta pesquisa não seja explicar os motivos das divergências apuradas nos valores de custos unitários dos produtos conforme a metodologia de custeio empregada, parte relevante dessa diferença pode ser explicada pela forma como estes métodos lidam com a ociosidade, como mencionado nas próximas seções, iniciando-se pelo confronto entre o UEP e o TDABC. 


\subsection{Comparativo entre UEP e TDABC}

No âmbito destes dois métodos, a mensuração da ociosidade pode ser realizada a partir da informação da capacidade instalada para determinado período. No caso do UEP, a etapa que mensura o "potencial produtivo" em termos de UEPs por hora em cada posto operativo proporciona a principal informação requerida para conhecer a ociosidade fabril, conforme descrito na Tabela 3.

Tabela 3 - Capacidade de UEPs instalada, utilizada e ociosa

\begin{tabular}{|c|c|c|c|c|c|c|}
\hline Postos Operativos & $\begin{array}{r}\text { Potencial } \\
\text { Produtivo } \\
\text { (UEPs/hora) } \\
(1) \\
\end{array}$ & $\begin{array}{r}\text { Expediente } \\
\text { Mensal } \\
\text { (em horas) } \\
(2)\end{array}$ & $\begin{array}{r}\text { Capacidade } \\
\text { Instalada de } \\
\text { UEPs no mês } \\
(3=1 \times 3) \\
\end{array}$ & $\begin{array}{r}\text { Capacidade } \\
\text { Utilizada de } \\
\text { UEPs no mês } \\
(4)\end{array}$ & $\begin{array}{r}\text { Capacidade } \\
\text { Ociosa em } \\
\text { UEPs no mês } \\
(5=3-4)\end{array}$ & $\begin{array}{r}\text { Capacidade } \\
\text { Ociosa em } \\
\text { UEPs/mês }(\%) \\
(6=5 / 3)\end{array}$ \\
\hline Entr.Pç./Micro+Impress. & 2,8654 & 198,00 & 567,35 & 242,51 & 324,84 & $57,26 \%$ \\
\hline Entr.Pç./Balança Dig. & 0,7000 & 198,00 & 138,59 & 2,59 & 136,00 & $98,13 \%$ \\
\hline Manual/Sep. Peças & 1,1118 & 198,00 & 220,14 & 57,49 & 162,65 & $73,88 \%$ \\
\hline Lavagem/Lavadora & 2,0764 & 198,00 & 411,12 & 244,10 & 167,02 & $40,63 \%$ \\
\hline $\begin{array}{l}\text { Secagem/Secadora } \\
\text { Outros }\end{array}$ & 2,2123 & 198,00 & 438,03 & 118,91 & 319,12 & $72,85 \%$ \\
\hline Totais & - & - & $3.276,97$ & 982,02 & $2.294,95$ & $76,40 \%$ \\
\hline
\end{tabular}

Fonte: elaborada pelos autores.

No Posto Operativo "Lavagem/Lavadora", por exemplo, o potencial produtivo (ou capacidade instalada) era de 2,0764 UEPs por hora. Se o expediente mensal era de 198 horas, a capacidade disponível/instalada no período era de 411,12 UEPs (198 horas X 2,0764 UEPs). Contudo, o volume produzido no mês consumiu somente 244,10 UEPs daquele limite de capacidade, acarretando ociosidade de 167,02 UEPs (ou 40,63\%) neste posto. Com o mesmo raciocínio sendo aplicado aos demais postos operativos, chegou-se aos totais em termos da "capacidade instalada" no mês (3.276,97 UEPs), da "capacidade utilizada" (982,02 UEPs) no período e da "capacidade ociosa" respectiva (2.294,95 UEPs). Com isso, a ociosidade média dos dez postos operativos foi de $76,40 \%$.

Em relação ao TDABC, a mensuração da ociosidade prioriza o tempo (em minutos) da capacidade prática do setor (equivalente ao expediente mensal disponível) e o consumo de tempo pela produção mensal, como demonstrado na Tabela 4.

Tabela 4 - Ociosidade em minutos, percentual e valor monetário (TDABC)

\begin{tabular}{l|r|r|r|r}
\hline & $\begin{array}{r}\text { Expediente } \\
\text { Mensal (min.) } \\
\text { Setores/Atividades }\end{array}$ & $\begin{array}{r}\text { Consumo de } \\
\text { Minutos/mês } \\
(\mathrm{b})\end{array}$ & $\begin{array}{r}\text { Ociosidade } \\
\text { Mensal (min.) } \\
(\mathrm{c}=\mathrm{a}-\mathrm{b})\end{array}$ & $\begin{array}{r}\text { Ociosidade } \\
\text { Mensal }(\%) \\
(\mathrm{d}=\mathrm{c} / \mathrm{a})\end{array}$ \\
\hline Entr.Pç./Micro+Impress. & 11.880 & $5.078,00$ & $6.802,00$ & $57,26 \%$ \\
Entr.Pç./Balança Dig. & 11.880 & 222,00 & $11.658,00$ & $98,13 \%$ \\
Manual/Sep. Peças & 11.880 & $3.102,50$ & $8.777,50$ & $73,88 \%$ \\
Lavagem/Lavadora & 11.880 & $7.053,67$ & $4.826,33$ & $40,63 \%$ \\
Outros & $\ldots$ & $\ldots$ & $\ldots$ & $\ldots$ \\
\hline Totais & 118.800 & $28.039,84$ & $90.760,16$ & $76,40 \%$ \\
\hline
\end{tabular}

Fonte: elaborada pelos autores.

No setor "Lavagem/Lavadora" havia 11.880 minutos disponíveis (198 horas de expediente mensal X 60 minutos). Como foram utilizados somente 7.053,67 minutos pela produção do mês, acarretou ociosidade de 4.826,33 minutos no período (ou 40,63\%) neste segmento. Ao computar todos os setores se verificou que o consumo total foi de $28.039,84$ minutos. Ao deduzir esse montante consumido dos 118.800 minutos da capacidade prática, restaram 90.760,16 minutos de capacidade ociosa (média de 76,40\% entre os dez setores). 
A partir desses volumes de capacidades instalada, utilizada e ociosa foi possível atribuir valor monetário (R\$) a estes níveis de atividade, como exposto na Tabela 5, para o TDABC.

Tabela 5 - Atribuição de valor (R\$) às capacidades disponível, utilizada e ociosa (TDABC)

\begin{tabular}{l|r|r|r|r} 
& $\begin{array}{r}\text { Taxa da } \\
\text { Capacidade } \\
\text { do Setor no } \\
\text { Mês (em R\$) }\end{array}$ & $\begin{array}{r}\text { Capacidade } \\
\text { Disponível } \\
\text { Min./mês } \\
(\mathrm{em} \mathrm{R} \$)\end{array}$ & $\begin{array}{r}\text { Capacidade } \\
\text { Utilizada } \\
\text { Min./mês } \\
(\mathrm{em} \mathrm{R} \$)\end{array}$ & $\begin{array}{r}\text { Capacidade } \\
\text { Ociosa } \\
\text { Min./mês } \\
(\mathrm{em} \mathrm{R} \$)\end{array}$ \\
\hline Entr.Pç./Micro+Impress. & 0,18744 & $2.226,81$ & 951,83 & $1.274,98$ \\
Entr.Pç./Balança Dig. & 0,04579 & 543,96 & 10,16 & 533,79 \\
Manual/Sep. Peças & 0,07273 & 864,02 & 225,64 & 638,38 \\
Lavagem/Lavadora & 0,13583 & $1.613,63$ & 958,08 & 655,55 \\
Secagem/Secadora & 0,14472 & $1.719,23$ & 466,72 & $1.252,51$ \\
Passadoria/Mesa de passar & 0,19500 & $2.316,59$ & 866,20 & $1.450,39$ \\
Embalag./Embal.Roupas & 0,04236 & 503,26 & 77,80 & 425,47 \\
Armaz./Cabideiro Eletr. & 0,06771 & 804,35 & 39,20 & 765,15 \\
Armaz./Manual-Prateleira MDF & 0,06143 & 729,73 & 59,03 & 670,70 \\
Saída Pç./Micro-comp. & 0,12965 & $1.540,27$ & 199,66 & $1.340,61$ \\
\hline Totais & & $12.861,86$ & $3.854,34$ & $9.007,52$ \\
\hline Percentual da capacidade total (\%) & & $100,00 \%$ & $29,97 \%$ & $70,03 \%$ \\
\hline
\end{tabular}

Fonte: elaborada pelos autores.

Pela concepção do TDABC, o custo da capacidade prática disponível no período abrange todos os custos de manter tal estrutura produtiva. No caso em lume, conforme evidenciado anteriormente na Tabela 1, esse montante foi de R $\$ 12.861,86$ para os 118.800 minutos de trabalho disponíveis (citados na Tabela 4). Ao multiplicar $(i)$ o total dos minutos de expediente disponíveis em cada setor pelo $(\mathrm{ii})$ valor monetário da respectiva taxa de capacidade prática, apurou-se o valor de $\mathrm{R} \$ 12.861,86$ (terceira coluna da Tabela 5). Contudo, o volume produzido no período consumiu apenas uma parte dessa capacidade prática instalada $(28.039,84$ minutos), como expresso na terceira coluna da Tabela 4. Isso implicou alocação de custos no valor de R $\$ 3.854,34$ (ou 29,97\% do total do mês, como consta da penúltima coluna da Tabela 5). Assim, a ociosidade apurada chegou ao montante de $\mathrm{R} \$ 9.007,52$ e equivale a $70,03 \%$ do custo total da estrutura fabril da empresa pesquisada.

Ainda, é pertinente destacar que os percentuais de ociosidade em valor e em minutos divergem porque alguns setores têm taxa de capacidade prática com valores menores que outros. Então, se a ociosidade for maior num setor com valor de custo inferior por minuto, refletirá no valor do percentual médio final da empresa.

No caso do método UEP, as alocações dos valores monetários às capacidades utilizadas e ociosas dos postos operativos podem ser efetuadas nos moldes do descrito na Tabela $6 . \mathrm{Na}$ parte inicial da Tabela 6 constam os níveis de capacidade instalada em termos de UEPs por mês em cada posto operativo e o total mensal da empresa (3.276,97 UEPs), além do nível de capacidade utilizada (que totalizou 982,02 UEPs) e da capacidade ociosa do período (total de 2.294,95 UEPs). Como o valor unitário da UEP no mês foi de R\$ 13,0974 (parte central da Tabela 6), bastou multiplicar esse valor (em R\$) pelo nível de UEPs das capacidades utilizadas e ociosas dos postos para determinar o valor monetário respectivo, como expresso nas duas colunas numéricas da parte inferior da tabela citada. Destarte, chegou-se aos montantes de R\$ $12.861,86$ para a capacidade utilizada e de $\mathrm{R} \$ 30.057,90$ para o nível de ociosidade apurado. Este último é um valor monetário inconsistente, pois está "descolado" da realidade da empresa pesquisada ao superar o custo total da fábrica no período. Por isso, cabe analisar com mais detalhes esse resultado. 
Tabela 6 - Atribuição de valor (RS) às capacidades disponível, utilizada e ociosa (UEP)

\begin{tabular}{|c|c|c|c|}
\hline \multicolumn{4}{|c|}{ A) Capacidade disponível, utilizada e ociosa nos postos operativos } \\
\hline Postos Operativos & $\begin{array}{r}\text { Capacidade } \\
\text { Disponível } \\
\text { (UEPs/mês) }\end{array}$ & $\begin{array}{r}\text { Capacidade } \\
\text { Utilizada } \\
\text { (UEPs/mês) }\end{array}$ & $\begin{array}{r}\text { Capacidade } \\
\text { Ociosa } \\
\text { (UEPs/mês) }\end{array}$ \\
\hline Entr.Pç./Micro+Impress. & 567,35 & 242,51 & 324,84 \\
\hline Entr.Pç./Balança Dig. & 138,59 & 2,59 & 136,00 \\
\hline Manual/Sep. Peças & 220,14 & 57,49 & 162,65 \\
\hline Lavagem/Lavadora & 411,12 & 244,10 & 167,02 \\
\hline Secagem/Secadora & 438,03 & 118,91 & 319,12 \\
\hline Passadoria/Mesa de passar & 590,23 & 220,69 & 369,53 \\
\hline Embalag./Embal.Roupas & 128,22 & 19,82 & 108,40 \\
\hline Armaz./Cabideiro Eletr. & 204,93 & 9,99 & 194,95 \\
\hline Armaz./Manual-Prat.MDF & 185,92 & 15,04 & 170,88 \\
\hline Saída Pç./Micro-comp. & 392,43 & 50,87 & 341,56 \\
\hline Totais & $3.276,97$ & 982,02 & $2.294,95$ \\
\hline \multicolumn{3}{|c|}{ B) Valor da UEP no mês: } & $\mathrm{R} \$ 13,0974$ \\
\hline \multicolumn{4}{|c|}{$\mathrm{C}=\mathrm{A} \times \mathrm{B}$ ) Valor monetário da capacidade disponível, utilizada e ociosa nos postos operativos } \\
\hline \multicolumn{2}{|l|}{ Postos Operativos } & $\begin{array}{r}\text { Capacidade } \\
\text { Utilizada } \\
(\mathrm{em} \mathrm{R} \$)\end{array}$ & $\begin{array}{r}\text { Capacidade } \\
\text { Ociosa } \\
(\mathrm{em} \mathrm{R} \$) \\
\end{array}$ \\
\hline \multicolumn{2}{|l|}{ Entr.Pç./Micro+Impress. } & $3.176,24$ & $4.254,59$ \\
\hline \multicolumn{2}{|l|}{ Entr.Pç./Balança Dig. } & 33,92 & $1.781,25$ \\
\hline \multicolumn{2}{|l|}{ Manual/Sep. Peças } & 752,96 & $2.130,25$ \\
\hline \multicolumn{2}{|l|}{ Lavagem/Lavadora } & $3.197,10$ & $2.187,55$ \\
\hline \multicolumn{2}{|l|}{ Secagem/Secadora } & $1.557,44$ & $4.179,60$ \\
\hline \multicolumn{2}{|l|}{ Passadoria/Mesa de passar } & $2.890,51$ & $4.839,92$ \\
\hline \multicolumn{2}{|l|}{ Embalag./Embal.Roupas } & 259,61 & $1.419,77$ \\
\hline \multicolumn{2}{|l|}{ Armaz./Cabideiro Eletr. } & 130,82 & $2.553,28$ \\
\hline \multicolumn{2}{|l|}{ Armaz./Manual-Prat.MDF } & 196,98 & $2.238,11$ \\
\hline \multicolumn{2}{|l|}{ Saída Pç./Micro-comp. } & 666,28 & $4.473,58$ \\
\hline Totais & & $12.861,86$ & $30.057,90$ \\
\hline Percentual da capacidade total $(\%)$ & & $29,97 \%$ & $70,03 \%$ \\
\hline
\end{tabular}

Fonte: elaborada pelos autores.

Os valores apurados revelaram uma divergência entre os dois métodos em análise. Enquanto que o total dos níveis de capacidade utilizada e ociosa (em termos de minutos no TDABC e de UEPs); no outro método apresentaram os mesmos percentuais em ambas metodologias (vide as últimas colunas das Tabelas 3 e 4), os valores monetários atribuídos à ociosidade foram distintos: $\mathrm{R} \$ 30.057,90$ no âmbito do UEP e R \$ 9.007,52 no caso do TDABC.

A principal causa dessa diferença está relacionada à forma como os dois métodos efetuam a alocação dos custos aos produtos. No TDABC inicialmente é priorizada a atribuição do valor total ( $\mathrm{R} \$)$ dos custos aos minutos da capacidade prática instalada. Posteriormente, estes são alocados aos produtos em decorrência do número de itens produzidos no período, cujo volume do mês é que determina a quantidade de minutos gastos no mesmo lapso temporal.

Pelo UEP o procedimento de custeio adota um roteiro distinto: o valor total (R\$) dos custos do período é integralmente alocado ao volume produzido de UEPs no mês. Depois disso é que se atribuiu um valor de custos aos produtos com base nos equivalentes em UEP respectivos. Ou seja, no TDABC primeiro se chega ao custo unitário do produto e depois se apura o custo do total do período pelo volume da produção e respectivo número de minutos consumidos (capacidade utilizada), que pode não ser a totalidade de tempo disponível (capacidade prática instalada). No UEP, em sentido oposto, o valor do custo total do mês é alocado integralmente à produção do período, mesmo que o potencial produtivo da fábrica não tenha sido efetivamente todo atingido. Essas duas características inerentes às metodologias de 
custeamento são responsáveis, a priori, pelas diferenças verificadas nos valores de custos unitários dos produtos apurados nesse estudo entre os dois métodos em evidência.

Para explicar numericamente a causa dessa divergência foi elaborada a Tabela 7, onde o valor da UEP foi calculado com base no volume efetivamente utilizado da capacidade instalada e, também, pelo nível de capacidade disponível.

Tabela 7 - Valor da UEP, conforme o nível de capacidade utilizado no cálculo

\begin{tabular}{lr}
\hline Itens & Valores \\
\hline a) Gasto mensal total (R\$) & $12.861,86$ \\
b) Quantidade de UEPs produzidas no mês (capacidade utilizada) & 982,02 \\
c) Quantidade de UEPs possíveis no mês (capacidade instalada ou potencial produtivo) & $3.276,97$ \\
d=a/b) Valor da UEP na quantidade produzida no mês (R\$) & 13,0974 \\
e=a/c) Valor da UEP na quantidade possível no mês (R\$) & 3,9249 \\
f=d-e) Diferença no valor da UEP (R\$) & 9,1725 \\
g=f/d) Diferença no valor da UEP (\%) & $70,033 \%$ \\
\hline
\end{tabular}

Fonte: elaborada pelos autores.

Exegese: o valor anteriormente utilizado para a UEP do mês era de R\$ 13,0974 e foi calculado pela divisão do ("a") custo fabril total $(\mathrm{R} \$ 12.861,86)$ pela ("b") quantidade de 982,02 UEPs produzidas no período (ou a capacidade produtiva utilizada). Porém, se o valor total do custo (R\$12.861,86) for dividido pelo volume possível de UEPs a produzir (também conhecido como potencial produtivo total do mês ou capacidade instalada) de 3.276,97 UEPs, o valor unitário da UEP cairá para R \$ 3,9249. Portanto, apura-se uma alteração de R \$ -9,1725 (ou redução de -70,033\%), como apresentado nas duas últimas linhas da Tabela 7.

Ao utilizar esse valor de R 3,9249 para a UEP do mês, os resultados em termos de custo unitário seriam modificados e se igualariam aos valores apurados pelo TDABC. Esse comparativo está demonstrado na Tabela 8.

Tabela 8 - Comparativo do custo do produto "L. Edredon (pç.)" no nível de capacidade utilizado e disponível

\begin{tabular}{l|r|r|r|r}
\hline Postos Operativos/Setores & $\begin{array}{r}\mathrm{f}) \text { Equivalente } \\
\text { em UEP }\end{array}$ & $\begin{array}{r}\mathrm{g}=\mathrm{fXd} \text { ) Custo } \\
\text { Unit. UEP (R\$) }\end{array}$ & $\begin{array}{r}\text { 3=fXe) Custo } \\
\text { Unit. UEP (R\$) }\end{array}$ & $\begin{array}{r}\text { 4) Custo unit. } \\
\text { TDABC (R\$) }\end{array}$ \\
\hline Entr.Pç./Micro+Impress. & 0,0955 & 1,2510 & 0,3749 & 0,3749 \\
Manual/Sep. Peças & 0,0278 & 0,3640 & 0,1091 & 0,1091 \\
Lavagem/Lavadora & 0,5191 & 6,7988 & 2,0374 & 2,0374 \\
Secagem/Secadora & 0,2765 & 3,6219 & 1,0854 & 1,0854 \\
Embalag./Embal.Roupas & 0,0324 & 0,4241 & 0,1271 & 0,1271 \\
Armaz./Manual-Prat.MDF & 0,0156 & 0,2050 & 0,0614 & 0,0614 \\
Saída Pç./Micro-comp. & 0,0330 & 0,4326 & 0,1297 & 0,1297 \\
\hline Totais & 1,0000 & 13,0974 & 3,9249 & 3,9249 \\
\hline
\end{tabular}

Fonte: elaborada pelos autores.

Na Tabela 8, a coluna 2 mostra os "equivalentes em UEP" do produto "L. Edredon (pç.)" em cada posto operativo pelo qual o mesmo passou para ser produzido. Na coluna seguinte está o cálculo do custo unitário deste item considerando o valor inicial da UEP, ou seja, o valor de R\$ 13,0974 (conforme calculado na linha "d" da Tabela 7, anteriormente). Por exemplo: na etapa "Lavagem/lavadora" o equivalente em UEP deste produto é 0,5191 , que multiplicado pelo valor de R $\$ 13,0974$ evidencia que o custo fabril da passagem do produto neste posto operativo é de $\mathrm{R} \$ 6,7988$. Ao fazer esse procedimento para todos os postos pelos quais o produto percorre para ser concluído, chega-se ao valor de R\$13,0974 como custo unitário. Como esse item é o "produto-base", o mesmo equivale a "1,0000 UEP", cujo valor no mês também é R\$ 13,0974. 
Por outro lado, caso o valor da UEP fosse de R\$ 3,9249 (se apurado conforme a linha “e” da Tabela 7), o valor do custo unitário desse produto passaria de $\mathrm{R} \$ 13,0974$ para $\mathrm{R} \$ 3,9249$, conforme apresentado na coluna 4 da Tabela 8, acima. Esse valor seria rigorosamente igual ao apurado pelo TDABC, como evidenciado na última coluna da tabela referida.

$\mathrm{O}$ cenário exposto, de igualdade nos valores do custo unitário do produto, tanto no TDABC quanto no UEP (quando computada somente a capacidade efetivamente utilizada no cálculo do valor da UEP do período), corrobora que a principal causa da diferença no valor da ociosidade está atrelada totalmente à forma pela qual os dois métodos efetuam a alocação dos custos aos produtos, como já comentado. Nesse ponto, o busílis dessa distinção pode estar ligado ao que Bornia (1995 e 2009) chama de princípios de custeio (integral versus ideal), cuja discussão será retomada mais adiante neste artigo.

\subsection{Comparativo entre ABC e UEP}

Ao confrontar o ABC com o UEP, os valores apurados como custo unitário de fabricação dos cinco produtos foram diferentes, como apontado na Tabela 2, em seção precedente. Nesse sentido, a Tabela 9 apresenta um detalhamento da composição do custo unitário do produto "L. Edredon (pç.)" por essas duas formas de custeio, a título de exemplo.

Tabela 9 - Comparativo das diferenças entre ABC e UEP do produto "L. Edredon (pç.)"

\begin{tabular}{|c|c|c|c|c|c|c|}
\hline \multirow[b]{3}{*}{ Postos Operativos/Atividades } & \multicolumn{2}{|c|}{ UEP } & \multicolumn{2}{|c|}{$\mathrm{ABC}$} & \multirow{2}{*}{\multicolumn{2}{|c|}{$\begin{array}{c}\text { Diferenças entre } \\
\text { UEP e ABC }\end{array}$}} \\
\hline & \multirow{2}{*}{$\begin{array}{r}\text { Custo Unit. } \\
(\mathrm{em} \mathrm{R} \$)\end{array}$} & \multirow{2}{*}{$\begin{array}{l}\% \text { do } \\
\text { Total }\end{array}$} & \multirow{2}{*}{$\begin{array}{r}\text { Custo Unit. } \\
\text { (em R\$) }\end{array}$} & \multirow{2}{*}{$\begin{array}{l}\% \text { do } \\
\text { Total }\end{array}$} & & \\
\hline & & & & & $(\mathrm{em} \mathrm{R} \$)$ & $(\mathrm{em} \%)$ \\
\hline Entr.Pç./Micro+Impress. & 1,2510 & $9,55 \%$ & 1,4460 & $12,98 \%$ & $-0,195$ & $-15,59 \%$ \\
\hline Manual/Sep. Peças & 0,3640 & $2,78 \%$ & 0,5610 & $5,04 \%$ & $-0,197$ & $-54,12 \%$ \\
\hline Lavagem/Lavadora & 6,7988 & $51,91 \%$ & 3,2909 & $29,54 \%$ & 3,508 & $51,60 \%$ \\
\hline Secagem/Secadora & 3,6219 & $27,65 \%$ & 3,5062 & $31,48 \%$ & 0,116 & $3,19 \%$ \\
\hline Embalag./Embal.Roupas & 0,4241 & $3,24 \%$ & 0,5758 & $5,17 \%$ & $-0,152$ & $-35,78 \%$ \\
\hline Armaz./Manual-Prat.MDF & 0,2050 & $1,56 \%$ & 0,7593 & $6,82 \%$ & $-0,554$ & $-270,46 \%$ \\
\hline Saída Pç./Micro-comp. & 0,4326 & $3,30 \%$ & 1,0002 & $8,98 \%$ & $-0,568$ & $-131,18 \%$ \\
\hline Totais & 13,0974 & $100,00 \%$ & 11,1394 & $100,00 \%$ & 1,958 & $14,95 \%$ \\
\hline
\end{tabular}

Fonte: elaborada pelos autores.

Embora o valor final do custo unitário pelos dois métodos tenha divergido em 14,95\% (ou R\$1,958), conforme mencionado na última coluna da Tabela 9, é pertinente salientar que os valores relacionados a cada posto operativo (UEP) ou atividade (ABC) tiveram variações percentuais bastante díspares. Enquanto no PO/Atividade "Secagem/Secadora" a diferença foi de apenas 3,19\%, nas demais etapas fabris os percentuais oscilaram entre $-15,59 \%$ (“Entr.Pç./Micro+Impress.”) e -270,46\% (“Armaz./Manual-Prat.MDF”).

Além disso, em termos de valor monetário (penúltima coluna) cabe destacar a divergência verificada na etapa "Lavagem/Lavadora", da ordem de R\$ 3,508. Ou seja, pelo UEP o valor relativo a este posto operativo chegou a $\mathrm{R} \$ 6,7988$ e, no caso da aplicação do $\mathrm{ABC}$, a atividade respectiva foi custeada com $\mathrm{R} \$ 3,2909$ (menos da metade do valor anterior).

Quanto à capacidade ociosa mensurada a partir do $\mathrm{ABC}$, nesta pesquisa tal informação foi obtida conforme expresso na Tabela 10. A partir do levantamento do número de atividades executadas (evidenciado na parte inicial da Tabela 10) e respectivo tempo médio de execução/duração (idem aos utilizados no cálculo do TDABC, só que convertidos para "horas", em vez de "minutos"), foi possível apurar o consumo total de horas no mês em tela (última coluna da parte intermediária da tabela citada). Ou seja, as 123 execuções da atividade "Lavagem/Lavadora" consumiram 117,56 horas no mês. 
Tabela 10 - Capacidade utilizada e ociosa pelo ABC

\begin{tabular}{|c|c|c|c|c|c|c|}
\hline \multicolumn{7}{|c|}{ a) Número de atividades executadas no mês } \\
\hline Atividades/Produtos & L.Edredon(pç.) & L.Camisa(pç.) & Terno(pç.) & L.Roup/Pas.(kg) & L.Roup/S/Pas.(kg) & Totais \\
\hline Entr.Pç./Micro+Impress. & 295 & 413 & 166 & 374 & 292 & 1.540 \\
\hline Entr.Pç./Balança Dig. & - & - & - & 374 & 292 & 666 \\
\hline Manual/Sep. Peças & 295 & 413 & 166 & 374 & 292 & 1.540 \\
\hline Lavagem/Lavadora & 74 & 6 & 9 & 19 & 15 & 123 \\
\hline Secagem/Secadora & 74 & 6 & 9 & 19 & 15 & 123 \\
\hline Outros & $\ldots$ & $\ldots$ & $\ldots$ & $\ldots$ & $\ldots$ & $\ldots$ \\
\hline \multicolumn{7}{|c|}{ b) Consumo de horas pelas atividades executadas no mês } \\
\hline Atividades/Produtos & L.Edredon(pç.) & L.Camisa(pç.) & L.Terno(pç.) & L. Roup/Pas.(kg) & L.Roup/S/Pas.(kg) & Totais \\
\hline Entr.Pç./Micro+Impress. & 9,83 & 13,77 & 5,53 & 31,17 & 24,33 & 84,63 \\
\hline Entr.Pç./Balança Dig. & - & - & - & 2,08 & 1,62 & 3,70 \\
\hline Manual/Sep. Peças & 7,38 & 6,88 & 4,15 & 18,70 & 14,60 & 51,71 \\
\hline Lavagem/Lavadora & 73,75 & 5,90 & 4,61 & 18,70 & 14,60 & 117,56 \\
\hline Secagem/Secadora & 36,88 & 0,10 & 0,13 & 9,35 & 7,30 & 53,75 \\
\hline Outros & $\ldots$ & $\ldots$ & $\ldots$ & $\ldots$ & $\ldots$ & $\ldots$ \\
\hline
\end{tabular}

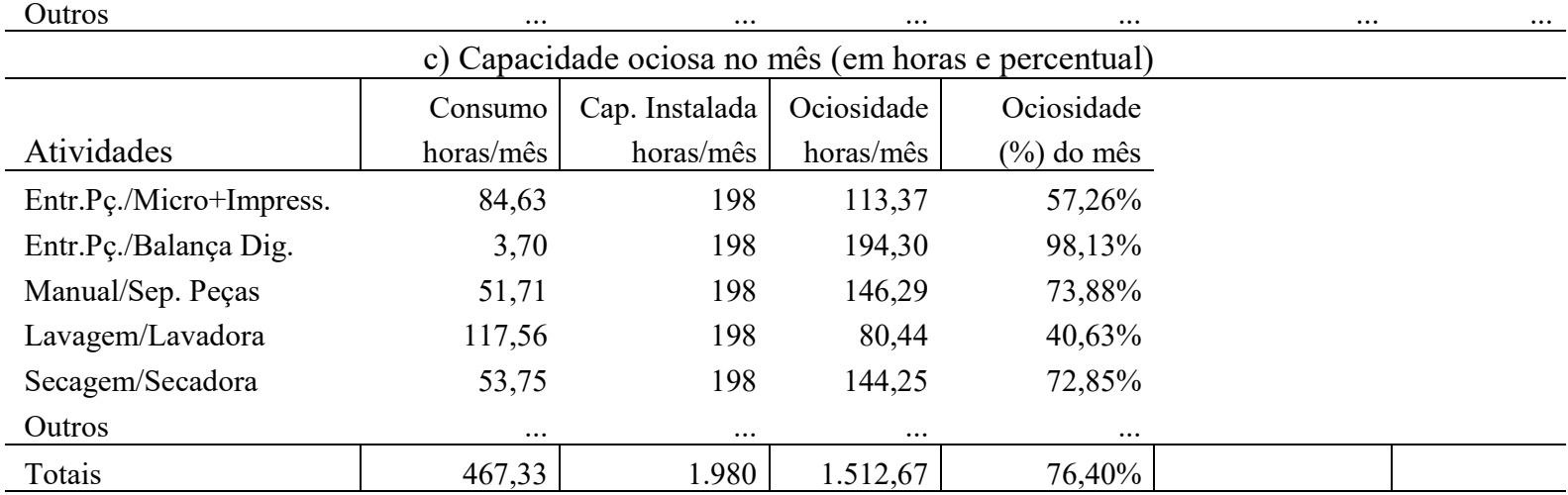

Fonte: elaborada pelos autores.

Ainda, no terço inferior da Tabela 10, para cada atividade abrangida foi descontado do ( $i$ ) número de horas do expediente mensal (capacidade instalada de horas/mês) o (ii) volume total de horas despendidas com essas atividades. Desta forma, apurou-se o volume de horas ociosas do mês (quarta coluna da última parte inferior da Tabela 10). Em seguida, na última coluna foram calculados os percentuais de cada atividade, sendo que nível médio de ociosidade chegou a $76,40 \%$, que é o mesmo percentual identificado nos outros dois métodos.

\subsection{Discussão dos resultados}

Quanto ao confronto do UEP com o TDABC, as divergências nos valores dos custos unitários dos produtos podem ser associadas à forma como os métodos abrangidos neste estudo são impactados pela ociosidade fabril do período que serviu de base para o custeio dos itens. Contudo, os valores inerentes à ociosidade podem ser classificados como "efeitos", pois têm origem na forma adotada pelos métodos de custeamento. Ou seja, a "causa" pode ser atribuída à decisão de custear integralmente os produtos pelos custos incorridos no período ou efetuar esse custeamento levando em consideração exclusivamente a parcela de custos efetivamente consumida da capacidade instalada.

Neste ponto cabe destacar a distinção proposta inicialmente na tese de doutorado de Bornia (1995), aprimorada posteriormente pelo mesmo autor em livro (BORNIA, 2009), acerca de "princípios" e "métodos" de custeio. Nesse caso, referido autor pugna que os métodos de custeio se referem a "como" os dados são processados para obter as informações de custos, voltando-se precipuamente à forma de alocação dos custos fixos e variáveis aos produtos. 
Porém, antes de alocar os custos aos produtos é necessário determinar qual parcela destes custos (em R\$) deve ser levada em consideração. Esse procedimento deve anteceder a aplicação do método de custeio e relaciona-se com a escolha de um entre os três princípios de custeio existentes (absorção integral, variável e absorção ideal), segundo a concepção do mencionado autor. No âmbito do princípio de custeio variável (ou direto), apenas os custos variáveis são alocados aos produtos, sendo os custos fixos atribuídos diretamente ao resultado do período. Porém, esse não é o foco desta pesquisa, visto que o contexto estudado está vinculado exclusivamente aos custos fixos (ou indiretos) da empresa em lume. Destarte, cabe discorrer sobre os outros dois princípios (integral versus ideal) para associá-los à realidade empresarial pesquisada. No custeio por absorção integral, o valor total dos custos do período é atribuído aos produtos, sem a segregação da parcela dos gastos que foi utilizada ineficientemente, como aquela ligada à ociosidade fabril. Por outro lado, no custeio por absorção ideal é efetuada essa distinção para descartar a alocação do montante gasto de forma ineficiente (como a ociosidade).

Os resultados apurados nesta pesquisa com os dados verídicos da lavanderia em tela, mesmo que percorrendo um caminho diferente, corroboram integralmente o raciocínio desenvolvido por Bornia (1995), conforme depreende-se do exposto na Tabela 7. Naquela tabela restou evidente que, ao distribuir o custo total do mês $(\mathrm{R} \$ 12.861,86)$ à produção efetiva do período (982,02 UEPs), a UEP custaria R\$13,0974 e englobaria a parcela cabível também à capacidade disponível que permaneceu ociosa. Por outro lado, caso o valor mensal (R\$ 12.861,86) fosse alocado ao volume possível de ser fabricado, com base no potencial produtivo total dos postos operativos dessa empresa no mês (3.276,97 UEPs), o custo unitário da UEP seria de R\$ 3,9249. Então, por essa última abordagem o valor da UEP passaria a ser apurado com o desconto da parcela dos gastos fixos ligados à capacidade instalada não utilizada (ociosidade), visto que os custos totais da produção levariam em conta somente a produção realizada no período (982,02 UEPs). Com isso, o valor final do custo unitário de cada produto igualar-se-ia àquele apurado pelo TDABC (vide Tabela 8), que levou em conta somente os minutos efetivamente utilizados na produção do mês.

Outra forma de explicar isso é que no método UEP o fluxo do cálculo parte do valor do custo total do período (R\$) em direção ao valor unitário da UEP (R\$), enquanto que no TDABC o roteiro percorre um caminho inverso, pois apura-se a taxa do custo de capacidade de cada setor por minuto $(\mathrm{R} \$)$ para, posteriormente, chegar-se ao valor do custo total do período ( $\mathrm{R} \$$ ). A partir disso verifica-se a ocorrência dos dois princípios de custeio mencionados por Bornia (1995), pois no âmbito do método UEP o valor do gasto total mensal (R\$) é integralmente alocado à produção do período (em UEPs), conforme a concepção do custeio por absorção integral, independentemente de haver ou não ociosidade do potencial produtivo da empresa. No caso do TDABC, o valor do custo total da produção do mês (R\$) é determinado com base na quantidade de minutos consumidos pela produção respectiva (a capacidade utilizada), que tende a ser menor que a capacidade prática instalada, o que acarreta a ociosidade fabril. Desse modo, equipara-se às características inerentes ao custeio por absorção ideal.

Saliente-se, ainda, a validação dos resultados apurados na pesquisa de Wernke, Junges e Lembeck (2015) acerca das seguintes semelhantes e divergências identificáveis nestes dois métodos: (i) uso exclusivo do fator "tempo de produção" para alocar custos aos produtos: minutos por unidade (TDABC) e tempo de passagem (em fração de horas) dos produtos pelos postos operativos (UEP); (ii) definição da capacidade produtiva: capacidade prática em minutos (TDABC) e potencial produtivo em UEPs por hora (potencial produtivo); (iii) prioridade à determinação do valor (em $\mathrm{R} \$$ ) de uma unidade abstrata para custear os produtos: no TDABC é a taxa de custo de capacidade do setor e no UEP o valor monetário respectivo; $(i v)$ permitem mensurar a capacidade fabril ociosa: minutos não consumidos (TDABC) e nível de UEPs não aproveitadas no período (UEP) e $(v)$ alocação dos custos: o TDABC prioriza os minutos da capacidade instalada, enquanto que no UEP o foco é a produção total mensal de UEPs. 
Uma divergência adicional, contudo, foi constatada em relação ao artigo citado. Enquanto naquele os valores apurados como custos unitários dos produtos foram diferentes em termos de valores monetários e também divergiram em termos do percentual de ociosidade, nesta pesquisa os percentuais relativos à capacidade ociosa foram idênticos. Essa discrepância se deve ao aspecto anteriormente ressaltado da utilização do princípio de custeio integral versus o real. Como neste artigo assumiu-se que o valor da ociosidade deveria ser mensurado a partir do volume possível de produção (vide Tabela 7), verificou-se que tanto os valores monetários quanto os percentuais relativos à ociosidade podem ser iguais no contexto pesquisado.

Cabe destacar também que esses dois métodos poderiam ser utilizados para valorar estoques e custear produtos, pois permitem apurar as capacidades "disponível", "utilizada" e "ociosa" (como requerido pela NBC TG 16(R2), item 13), o que se adequa ao posicionamento de Schultz, Silva e Borgert (2008) mencionado anteriormente.

Quanto às diferenças de valores computados como custos unitários dos produtos no ABC e no UEP, estas decorrem principalmente das concepções de cálculo. Ou seja, no método UEP os valores apurados por produto estão atrelados ao estabelecimento das relações de esforço de fabricação (que se fundamenta, exclusivamente, no "tempo de passagem pelos postos") entre os itens elaborados no período, a partir do produto-base utilizado como referência nos cálculos. Por outro lado, no âmbito do $\mathrm{ABC}$ os custos totais das atividades são rateados (ou alocados) aos objetos de custeio (produtos, por exemplo) por intermédio do direcionadores de atividades selecionados. Estes direcionadores tendem a não considerar o tempo de execução das atividades, priorizando o número de vezes que tal atividade foi executada no mês. Destarte, enquanto no UEP se utiliza apenas um critério (tempo), no $\mathrm{ABC}$ geralmente são empregados diversos parâmetros (um para cada atividade priorizada) para alocação dos custos das atividades aos produtos e sem vínculo estreito com o tempo gasto nessas atividades. Esses mecanismos diferentes de alocação (tempo versus direcionadores), a priori, são os principais causadores da apuração de valores de custos unitários distintos, como identificado na Tabela 2, anteriormente.

No que se refere às divergências apuradas entre os custos pelo $\mathrm{ABC}$ e pelo TDABC, as causas podem ser atribuídas a dois aspectos. O primeiro relaciona-se com a disparidade de critérios de alocação, a exemplo do mencionado no parágrafo anterior (critério único - tempo para o TDABC e vários direcionadores para o $\mathrm{ABC}$, um para cada atividade). $\mathrm{O}$ segundo e mais relevante ponto para explicar as diferenças de valores entre os dois métodos diz respeito ao citado na seção precedente acerca dos princípios de absorção integral versus ideal. Enquanto que no $\mathrm{ABC}$ os custos das atividades são integralmente absorvidos pelas atividades executadas no mês (idem ao UEP), no TDABC isso não acontece, como já comentado. No $\mathrm{ABC}$, o produto receberá uma parcela do custo total da atividade, proporcional ao número de execuções desta que requereu no período, independentemente de haver ociosidade ou não (absorção integral). Por sua vez, no TDABC somente o custo do tempo efetivamente consumido será atribuído aos produtos, proporcionalmente ao consumo ocorrido (princípio de absorção ideal).

Acerca da mensuração da ociosidade, enquanto os métodos UEP e TDABC estão limitados à utilização do critério "tempo", por imposição do roteiro dos cálculos respectivos, o Custeio Baseado em Atividades (ABC) faculta a livre escolha entre diversos "direcionadores" para atribuir o custo das atividades aos produtos. Esses direcionadores até podem levar em conta o "tempo de duração" de cada atividade, se necessário, mas costumam ser determinados em função da sua proximidade com o volume de "execução" ou "ocorrência" destas no período.

Contudo, o caminho encontrado neste estudo para mensurar a ociosidade por intermédio do $\mathrm{ABC}$ implicou atribuir um tempo médio de execução para cada atividade (em horas) que, multiplicado pelo número de execuções destas no mês, permitiu medir o consumo do tempo de expediente disponível (conforme exposto na Tabela 10). Ao proceder desta forma, desvirtua-se a concepção básica deste método de vez que, segundo Pereira (2015), a escolha dos 
direcionadores é crucial para minimizar a arbitrariedade na alocação de custos, como proposto na concepção original do $\mathrm{ABC}$ para distingui-la das metodologias utilizadas até então.

\section{Considerações finais}

Esta pesquisa visou comparar os métodos $\mathrm{ABC}$, TDABC e UEP no que tange à evidenciação da ociosidade fabril. Nesse aspecto, os autores entendem que atingiram o objetivo do estudo, conforme relatado nas seções precedentes, pois a questão levantada (que indagava acerca da possibilidade de existir diferenças nos valores atribuíveis à ociosidade, se mensurada por essas três metodologias de custeamento) pôde ser convenientemente respondida.

Nesse sentido, quanto às contribuições do estudo é interessante destacar três aspectos. O primeiro é que os valores de custos unitários (em R $\$$ ) apurados pelos três métodos resultam diferentes se apurados pela concepção original destes, como exposto na Tabela 2. Uma parte significativa dessa diferença pode ser atribuída, principalmente, à maneira como essas formas de custeamento tratam a ociosidade. Enquanto no TDABC somente a capacidade efetivamente utilizada (em minutos) é alocada como custo aos produtos elaborados no período, nos métodos $\mathrm{UEP}$ e $\mathrm{ABC}$ isso não ocorre. Estes últimos, a priori, assumem que os gastos do período são atribuíveis à totalidade da produção respectiva (pelo volume de UEPs produzidas ou pelo volume de atividades executadas). A confirmação disso pode ser visualizada nas Tabelas 7 e 8 , onde é evidenciado que a adequação do cálculo do valor da UEP ao nível possível de produção (ao invés do nível efetivamente produzido), permite apurar custos unitários com valores monetários idênticos neste método e no TDABC.

A segunda conclusão relaciona-se à mensuração da ociosidade, pois constatou-se que nos três métodos é possível identificar a produção ociosa para atribuir-lhe valor monetário e verificar o percentual correspondente sobre a capacidade instalada. Nesse liame, nas Tabelas 3 e 4 apurou-se que o percentual de ociosidade foi idêntico $(76,40 \%)$ nos métodos UEP (com potencial produtivo instalado de 3.276,97 UEPs, capacidade efetivamente utilizada de 982,02 UEPs e ociosidade total de 2.294,95 UEPs) e TDABC (com 118.800 minutos de capacidade prática instalada, consumo efetivo de 28.039,84 minutos pela produção do período e ociosidade de 90.760,16 minutos). Por outro lado, ao multiplicar as taxas unitárias de custos nos dois métodos pelo nível de ociosidade de cada setor ou posto operativo ( $\$$ 13,0974 como valor da UEP para todos os postos operativos e custo por minuto de trabalho diferente em cada setor no caso do método TDABC), os valores totais foram diferentes: $\mathrm{R} \$ 30.057,90$ e $\mathrm{R} \$ 9.007,52$ para UEP e TDABC, respectivamente. Entretanto, esse valor da ociosidade total no método UEP é inconsistente. O correto seria apurá-lo a partir do montante possível de UEPs a fabricar pela capacidade instalada disponível (potencial produtivo), como descrito na Tabela 7, o que acarretaria uma redução no valor da UEP da ordem de 70,03\% (de R \$ 13,0974 para R \$ 3,9249) e igualaria os valores da ociosidade total e os custos unitários dos produtos (Tabela 8).

O terceiro ponto a salientar é que o ABC pode ser "adaptado" para gerar informações sobre a ociosidade fabril. Contudo, o procedimento utilizado na Tabela 10 acarreta um desvirtuamento da concepção original do método, pois requer a vinculação deste exclusivamente ao fator "tempo" de execução, como no TDABC, em vez da adoção de diversos direcionadores conforme a atividade em tela.

Por último, é pertinente ressalvar que um estudo de caso, por sua natureza, circunscreve as conclusões oriundas ao âmbito da entidade pesquisada. Contudo, os procedimentos adotados e a descrição efetuada ao longo do texto permitem que pesquisas posteriores sejam aplicadas a outros contextos empresariais. Por isso, recomenda-se que futuros estudos abordem esse tema em empresas de outros segmentos e portes para corroborar ou refutar os achados aqui relatados. 


\section{Referências}

AMBrogini, E. B. de M.; ALBUQUERQUE, A. A. de; SOUZA, K. G. de. Aplicação dos principais métodos de custeio em um consultório médico. In: XXI CONGRESSO BRASILEIRO DE CUSTOS. Natal, RN, nov./2014. Anais... Natal: UFRN, 2014.

ANDRADE, M. M. de. Como preparar trabalhos para cursos de pós-graduação: noções práticas. 5. ed. São Paulo: Atlas, 2002.

ATADAINE SOBRINHO, P. Estoques: normas internacionais de Contabilidade - IAS 2 e CPC 16 (Coleção IFRS). São Paulo: IOB, 2010.

BETTINGHAUS, B.; DEBRUINE, M.; SOPARIWALA, P. R. Idle capacity costs: it isn't just the expense. Management Accounting Quarterly, v.13, n.2, p.1-7, 2012.

BORNIA, A. C. Mensuração das perdas dos processos produtivos: uma abordagem metodológica de controle interno. Programa de Pós-Graduação em Engenharia de Produção, Universidade Federal de Santa Catarina, Florianópolis, março de 1995 (Tese de Doutorado).

BORNIA, A. C. Análise gerencial de custos: aplicação em empresas modernas. 2. ed. São Paulo: Atlas, 2009.

BUCHHEIT, S. Reporting the cost of capacity. Accounting, Organizations and Society, v.28, n.6, p.549-565, 2003. Disponível em: https://doi.org/10.1016/S0361-3682(02)00014 Acesso em: 15 dez. 2015.

CAMPAGNOLO, R. R.; SOUZA, J. S.; KLIEMANN NETO, F. J. Seria mesmo o Time-Driven ABC (TDABC) um método de custeio inovativo? Uma análise comparativa entre o TDABC e o método da Unidade de Esforço de Produção (UEP). In: XI CONGRESSO INTERNACIONAL DE COSTOS Y GESTION, 2009, Trelew. Anais do XI Congresso Internacional de Costos y Gestion, 2009.

CAMPANALE, C.; CINQUINI, L.; TENUCCI, A. Time-driven activity-based costing to improve transparency and decision making in healthcare: a case study. Qualitative Research in Accounting \& Management, v.11, n.2, p.165-186, 2014. Disponível em: https://doi.org/10.1108/QRAM-04-2014-0036. Acesso em: 20 dez. 2015.

CARDINAELS, E.; LABRO, E. On the determinants of measurement error in Time-Driven Costing. The Accounting Review, v.83, n.3, p.735-756, 2008. Disponível em: http://www.jstor.org/stable/30244499. Acesso em: 15 dez. 2015.

CONFESSOR, K. L. A.; SANTOS, H. F.; WALTER, F.; GOUVEIA, R. E. C.; LEITE, M. S. A. Análise comparativa dos métodos de custeio "Unidades de Esforço de Produção" e "Unités de Valeur Ajoutée”. In: CONGRESSO BRASILEIRO DE CUSTOS, 17, 2010, Belo Horizonte. Anais... Belo Horizonte: ABC/UFMG, 2010. CD-ROM.

DALMÁCIO, F. Z.; REZENDE, A. J.; AGUIAR, A. B. Uma aplicação do Time-Driven ABC Model no setor de serviço hospitalar: a nova abordagem ABC proposta por Kaplan e Anderson. Contabilidade Vista \& Revista, v.18, n.2, p.11-34, 2007.

DUARTE, S. L.; PINTO, K. C. R.; LEMES, S. Integração da teoria das filas ao Time-driven ABC Model: uma análise da capacidade ociosa. Enfoque: Reflexão Contábil. UEM (PR), v.28, n.1, p.40-53, 2009. DOI: 10.4025/enfoque.v28i1.8219

ECKERT, A.; BIASIO, R.; MECCA, M. S.; ROLOFF, S. Custo da ociosidade na indústria: estudo de caso em uma empresa calçadista do nordeste brasileiro. Exacta - EP, São Paulo, v.11, n.2, p.187-198, 2013. DOI: 10.5585/ExactaEP.v11n2.4208 
EVERAERT, P.; BRUGGEMAN, W. Time-Driven Activity-Based Costing: Exploring the underlying model. Cost Management, v.21, n.2, p.16-20, 2007.

EWER, S. R.; KELLER, C.; OLSON, S. K. No equivocating: expense those idle capacity costs. Strategic Finance, p.55-59, june/2010.

FONTOURA, F. B. B. da. Gestão de custos: uma visão integradora e prática dos métodos de custeio. São Paulo: Atlas, 2013.

GANTZEL, G.; ALLORA, V. Revolução nos custos. Salvador: Casa da Qualidade, 1996.

GIL, A. C. Métodos e técnicas de pesquisa social. 5. ed. São Paulo: Atlas, 1999.

GIRI, B. C.; MOON, I. Accounting for idle capacity cost in the scheduling of economic lot sizes. International Journal of Production Research, v.42, n.4, p.677-691, 2004. DOI: $10.1080 / 0020754031000164384$

GONÇALVES, B. do N.; CRUZ, V. L.; MORAIS, R. S. de; MEIRELES, J. M. da S.; BARBOSA JUNIOR, R. de LIMA; PEIXOTO, E. P. de A. Comparativo entre o custeio por absorção, custeio variável e o custeio abc em uma escola estadual. In: XXI CONGRESSO BRASILEIRO DE CUSTOS. Natal, nov./2014. Anais... Natal, RN, 2014.

IUDÍCIBUS, S. de; MARTINS, E.; GELBCKE, E. R.; SANTOS, A. dos. Manual de contabilidade societária: aplicável a todas as sociedades, de acordo com as normas internacionais e do CPC. São Paulo: Atlas, 2010.

KAPLAN, R. S. Improving value with TDABC. Healthcare Financial Management, v.68, n.6, p.76-83, 2014.

KAPLAN, R. S., COOPER, R. Custo e desempenho: administre seus custos para ser mais competitivo. São Paulo: Futura, 1998.

KAPLAN, R. S.; ANDERSON, S. R. Custeio baseado em atividade e tempo. Rio de Janeiro: Campus, 2007

MACHADO, A. de O.; BORGERT, A.; LUNKES, R. J. ABC e UEP: um ensaio em empresa de software. In: XIII CONGRESSO BRASILEIRO DE CUSTOS. Belo Horizonte. Anais... Belo Horizonte, 2006.

MALAQUIAS, R. F.; GIACHERO, O. S.; COSTA, B. E. da; LEMES, S. Método da unidade de esforço de produção versus métodos de custeio tradicionais: um contraponto. In: CONGRESSO BRASILEIRO DE CUSTOS, 14, 2007, João Pessoa. Anais... João Pessoa: ABC/UFMG, 2007. CD-ROM.

MARTINS, E.; ROCHA, W. Métodos de custeio comparados: custos e margens analisadas sob diferentes perspectivas. São Paulo: Atlas, 2010.

MAURICIO, A. L.; CAVENAGHI, W. Comparação entre métodos de custeio para análise gerencial de produtos: aplicação em uma empresa do setor de injeção de termoplásticos. In: CONGRESSO BRASILEIRO DE CUSTOS, 18, 2011, Rio de Janeiro. Anais... Rio de Janeiro: ABC/UCM, 2011. CD-ROM.

MORAES, M. R. Q. Diferenças e semelhanças entre o custeio baseado em atividade e custeio baseado em atividade e tempo. Dissertação (Mestrado Profissional em Economia) Universidade Federal do Rio Grande do Sul, Faculdade de Ciências Econômicas, Programa de Pós-graduação em Economia. Porto Alegre, 2011. 
PACASSA, F.; SCHULTZ, C. A. TDABC: uma proposta para implementação em um frigorífico de pequeno porte. In: CONGRESSO BRASILEIRO DE CUSTOS, 19, 2012, Bento Gonçalves. Anais... Bento Gonçalves: ABC/UCS, 2012. CD-ROM.

PEIXE, B. C. S.; BORNIA, A. C.; MARTINS, A. Utilização do método da unidade de esforço de produção e custeio. In: CONGRESSO BRASILEIRO DE CUSTOS, 17, 2010, Belo Horizonte. Anais... Belo Horizonte: ABC/UFMG, 2010. CD-ROM.

PEREIRA, A. R. Aplicabilidade do sistema de custeio baseado em atividade e tempo em indústria de bebidas. 2011. 144 f. Dissertação (Mestre em Economia) - Departamento de Programa de Pós-graduação em Economia, Universidade Federal do Rio Grande do Sul, Porto Alegre, 2011.

PEREIRA, S. I. M. Custeio por atividades (ABC) e unidade de esforço de produção (UEP): similaridades, diferenças e complementaridades. Dissertação (Mestrado). PPGCC. Universidade de São Paulo - USP, 2015.

PINZAN, A. F. Métodos de custeio e seus propósitos de uso: análise por meio de estudo de casos múltiplos. 126 fls. Dissertação (Mestrado). PPGCC. Universidade de São Paulo - USP, 2013.

POPESKO, B. How to calculate the costs of idle capacity in the manufacturing industry. Global Business and Management Research, v.1, n.2, p.19-26, 2009.

RATNATUNGA, J.; TSE, M. S. C.; BALACHANDRAN, K. R. Cost management in Sri Lanka: a case study on volume, activity and time as cost drivers. The International Journal of Accounting, v.47, p.281-301, 2012. DOI: 10.1016/j.intacc.2012.07.001

RIBEIRO, O. M. Contabilidade de custos: fácil. 5. ed. São Paulo: Saraiva, 1997.

RICHARDSON, R. J. Pesquisa social: métodos e técnicas. 3. ed. São Paulo: Atlas, 1999.

RUCINSKI, L. Um estudo sobre a similaridade de conceitos entre os métodos de custeio ABC e UEP e uma proposta de modelo de gestão de custos para os atuais sistemas de manufatura. Dissertação (Mestrado). PPGEP da Faculdade de Engenharia Mecânica, Universidade Estadual de Campinas. Campinas, 1996.

SABADIN, A.; GRUNOW, A.; FERNANDES, F. Integração do custeio ABC com o método UP: um estudo de caso. Revista Universo Contábil, v.1, n.3, p.21-36, 2005. DOI: http://dx.doi.org/10.4270/ruc.20051

SCHMIDT, P.; SANTOS, J. L.; LEAL, R. Time Driven Activity Based Costing (TDABC): uma ferramenta evolutiva na gestão de atividades. Revista Iberoamericana de Contabilidade de Gestión, n.14, jul./dez.2009.

SCHULTZ, C. A.; SILVA, M. Z. da; BORGERT, A. É o Custeio por Absorção o único método aceito pela Contabilidade? In: CONGRESSO BRASILEIRO DE CUSTOS, 15, 2008. Curitiba. Anais... Curitiba, 2008.

SHANK, J. K.; GOVINDARAJAN, V. Gestão estratégica de custos. Rio de Janeiro: Campus, 1993.

SILVA, M. Mensuração dos custos de procedimentos médicos em organizações hospitalares: sistematização de um método de custeio híbrido à luz do ABC e do UEP. Dissertação (Mestrado). PPGC da Universidade Federal de Santa Catarina. Florianópolis, 2006.

SILVA, M. Z. da; BORGERT, A.; SCHULTZ, C. A. Sistematização de um método de custeio híbrido para o custeamento de procedimentos médicos: uma aplicação conjunta das 
metodologias $\mathrm{ABC}$ e UEP. Revista de Ciências da Administração, v.11, n.23, p.217-244, 2009. DOI: $10.5007 / 11349$.

SILVA, M. Z. da. Mensuração dos custos de procedimentos médicos em organizações hospitalares: sistematização de um método de custeio híbrido à luz do $\mathrm{ABC}$ e da UEP. Dissertação (Mestrado em Contabilidade), Programa de Pós-Graduação em Contabilidade, Universidade Federal de Santa Catarina, Florianópolis. 2006.

SILVA, T. F. G. da; LEITE, M. S. A. A influência da gestão da capacidade na determinação do custo unitário de produção: um estudo de caso em uma empresa de embalagens plásticas flexíveis. Revista Produção Online, v.13, n.3, p.915-944, 2013. DOI: https://doi.org/10.14488/1676-1901.v13i3.1233

SLAVOV, T. N. Gestão estratégica de custos: uma contribuição para a construção de sua estrutura conceitual. Tese (doutorado). PPGCC. Faculdade de Economia, Administração e Contabilidade da Universidade de São Paulo - FEA/USP, São Paulo, 2013.

SOUZA, M. A. de; DIEHL, C. A. Gestão de custos: uma abordagem integrada entre contabilidade, engenharia e administração. São Paulo: Atlas, 2009.

TSE, M. S. C.; GONG, M. Z. Recognition of idle resources in Time-Driven Activity-Based Costing and Resource Consumption Accounting Models. Journal of Applied Management Accounting Research, v.7, n.2, p.41-54, 2009.

WERNKE, R., JUNGES, I., LEMBECK, M. Comparativo entre os métodos UEP e TDABC: estudo de caso. Revista Ambiente Contábil, v.7, n.1, p.51-69, 2015. DOI: 10.21680/21769036

WERNKE, R.; CLÁUDIO, D. A; JUNGES, I. Indicadores não-financeiros do método UEP aplicáveis à gestão de pequena indústria. Iberoamerican Journal of Industrial Engineering, v.4, n.8, p.125-145, 2013.

WERNKE, R.; MENDES, E. Z. M.; LEMBECK, M. ABC versus TDABC: estudo de caso em transportadora. In: CONGRESSO BRASILEIRO DE CUSTOS, 17, 2010, Belo Horizonte. Anais... Belo Horizonte: ABC/UFMG, 2010. CD-ROM.

YIN, R. K. Estudo de caso: planejamento e método. 4. ed. Porto Alegre: Bookman, 2010. 